\title{
Application of Defected Ground Structure to Suppress Out-of-Band Harmonics for WLAN Microstrip Antenna
}

\author{
Pravin Ratilal Prajapati \\ A. D. Patel Institute of Technology, Department of Electronics and Communication Engineering, Gujarat 388121, India \\ Correspondence should be addressed to Pravin Ratilal Prajapati; pravinprajapati05@gmail.com
}

Received 27 September 2015; Accepted 29 November 2015

Academic Editor: Dmitry Kholodnyak

Copyright (C) 2015 Pravin Ratilal Prajapati. This is an open access article distributed under the Creative Commons Attribution License, which permits unrestricted use, distribution, and reproduction in any medium, provided the original work is properly cited.

\begin{abstract}
An application of defected ground structure (DGS) to reduce out-of-band harmonics has been presented. A compact, proximity feed fractal slotted microstrip antenna for wireless local area network (WLAN) applications has been designed. The proposed 3rd iteration reduces antenna size by $43 \%$ as compared to rectangular conventional antenna and by introducing $\mathrm{H}$ shape DGS, the size of an antenna is further reduced by $3 \%$. The DGS introduces stop band characteristics and suppresses higher harmonics, which are out of the band generated by 1st, 2nd, and 3rd iterations. H shape DGS is etched below the $50 \Omega$ feed line and transmission coefficient parameters $\left(S_{21}\right)$ are obtained by CST Microwave Studio software. The values of equivalent $L$ and $C$ model have been extracted using a trial version of the diplexer filter design software. The stop band characteristic of the equivalent $L C$ model also has been simulated by the Advance Digital System software, which gives almost the same response as compared to the simulation of CST Microwave Studio V. 12. The proposed antenna operates from $2.4 \mathrm{GHz}$ to $2.49 \mathrm{GHz}$, which covers WLAN band and has a gain of $4.46 \mathrm{~dB}$ at $2.45 \mathrm{GHz}$ resonance frequency.
\end{abstract}

\section{Introduction}

Printed antennas have been widely used because of their advantages like low profile, easy fabrication, low cost, small size, and so forth $[1,2]$. To reduce the size of the antenna without much more adverse effect on bandwidth and the gain of an antenna, various methods have been proposed like using dielectric substrates with high permittivity [3], applying magneto inductive waveguide loading [4], and using notches or slots on patch antenna [5]. By embedding specific slot (fractal slot) on microstrip antenna, surface current path increases, which lowers the resonant frequency of an antenna, and thus antenna size reduction can be possible [6]. To improve radiation efficiency of the antenna, it becomes necessary to suppress higher harmonics, which cause loss of power. Higher harmonics also produce spurious radiation. To suppress higher harmonics, various techniques like PBG (photonic band gap structure) [7-10], Filter, and EBG (electromagnetic band gap structure) [11, 12] have been proposed. The conducting metal etched off in specific shape from the ground plane provides wide rejection band covering some frequency range [13-17]. The structure of this type is known as defected ground structure (DGS). The main advantages of DGS is that it introduces slow wave effect. This effect produced because of the DGS equivalent $L$ and $C$ components. The transmission line witH-DGS gives a higher effective impedance and also introduces high slow wave effect, which provides rejection band in some frequency range. The microstrip line witH-DGS has a large electrical length as compared to conventional microstrip for the same physical length. Thus, DGS helps to lower resonance frequency and therefore to reduce the size of an antenna [18].

In this paper, an application of the DGS to suppress higher harmonics and thus to improve radiation efficiency of the planar antenna is demonstrated. Moreover, this paper also shows the significant role of the fractal geometry for size miniaturization of the radiating element of the patch antenna.

\section{Antenna Geometry and Operational Mechanism}

The geometry of the proximity coupled patch antenna is presented in Figure 1. The argon material, which has a relative 


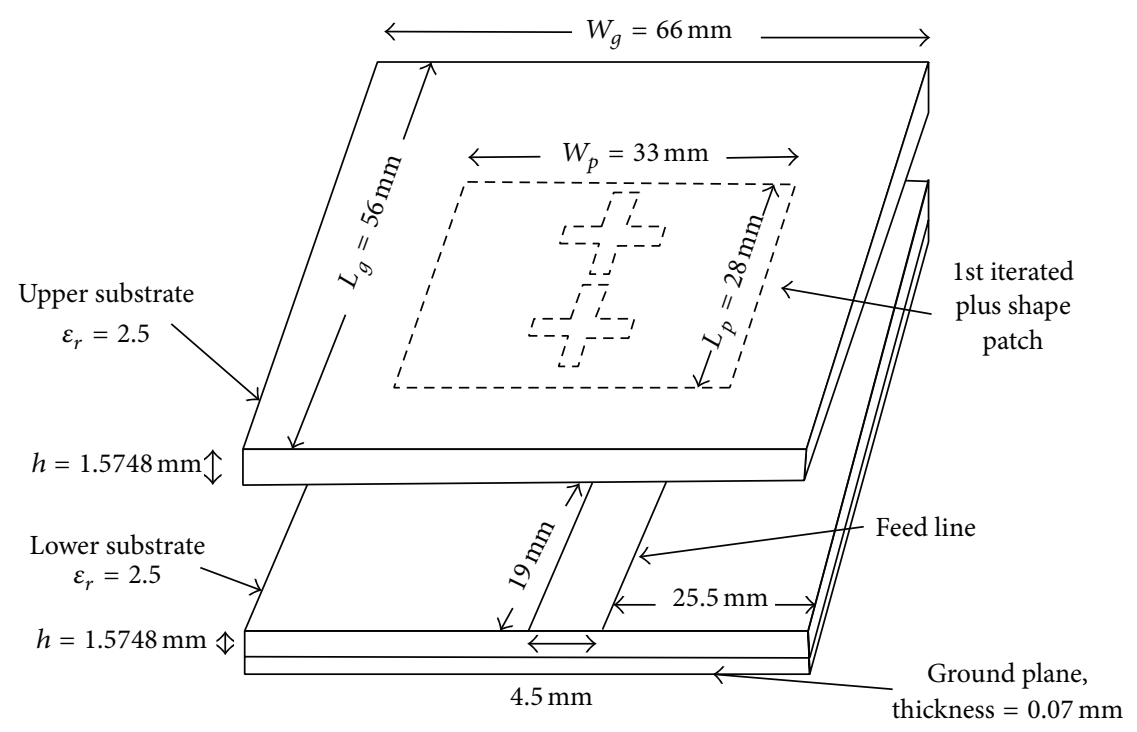

FIGURE 1: Geometry of proximity coupled plus shape fractal slot antenna.

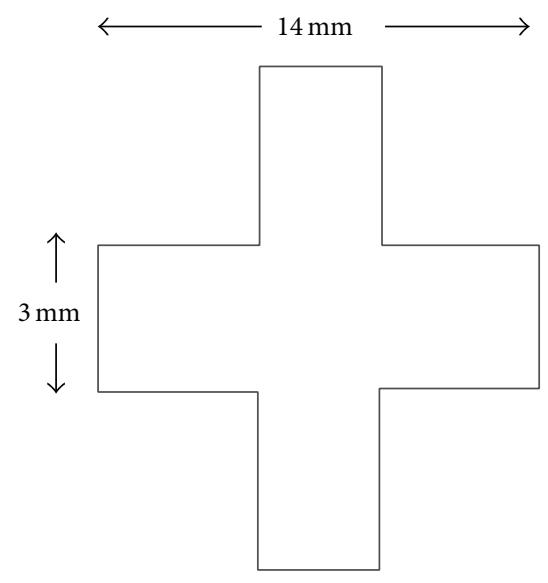

(a)

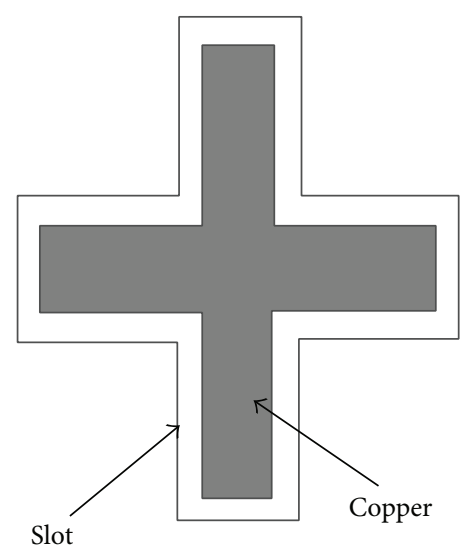

(b)

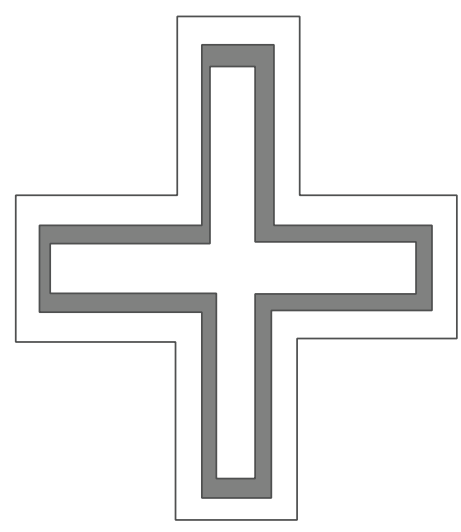

(c)

FIgURE 2: Geometry of plus shape fractal slot: (a) 1st iteration (b) 2nd iteration, (c) 3rd iteration.

permittivity $\varepsilon_{r}=2.5$, thickness $1.5748 \mathrm{~mm}$, and loss tangent 0.0025 , is used for both substrates. Low dielectric constant material has been selected to get good radiation efficiency. The ground plane dimensions are $W_{g} \times L_{g}=66 \times 56 \mathrm{~mm}^{2}$. The microstrip line with $50 \Omega$ impedance, width $W_{f}=$ $4.5 \mathrm{~mm}$, and length $L_{f}=19 \mathrm{~mm}$ is fabricated on upper side of the lower substrate and H shape DGS is etched out from the lower side (ground plane) of lower substrate. The number of DGS shapes such as hook shape [19], arc shape [20], concentric ring shape [21], and spiral shape [22] was reported. The reason of selection of $H$ shape DGS is that, as per parametric simulation, it was concluded that the effect of changing of length arm of $\mathrm{H}$ shape DGS $\left(L_{1}\right)$, width of arm $\left(L_{2}\right)$, distance between the two arms $\left(C_{1}\right)$, and so forth on cut-off frequency of DGS is almost linear. So it is easy to get specific bandstop region by selecting appropriate dimensions of $\mathrm{H}$ shape. The rectangular patch with size $W_{p} \times L_{p}=$ $33 \times 26 \mathrm{~mm}^{2}$ is fabricated on upper side of upper substrate.
From that patch, plus shape slot is taken out. This procedure is repeated for next two iterations as shown in Figure 2. Figure 3 shows inner dimensions of the plus shape slot. H shape DGS is created in the ground plane of the antenna. The dimensions and location of H shaped DGS are mentioned in Figure 4.

\section{Behavior of DGS as Band Stop Filter}

Initially, H-DGS is considered below the $50 \Omega$ microstrip line as shown in Figure 5. The microstrip line has a width of $4.5 \mathrm{~mm}$ considered from the calculation obtained by CST Microwave Studio, V. 12. The DGS cell is simulated by the same software and from $S_{21}$ parameters, it was concluded that H-DGS has characteristics of a one-pole band stop filter. For getting the desired value of upper edge and lower edge of band stop frequencies, specific dimension of H-DGS was varied by keeping other dimensions constant. The effect of H-DGS dimensions on upper edge and lower edge band stop 


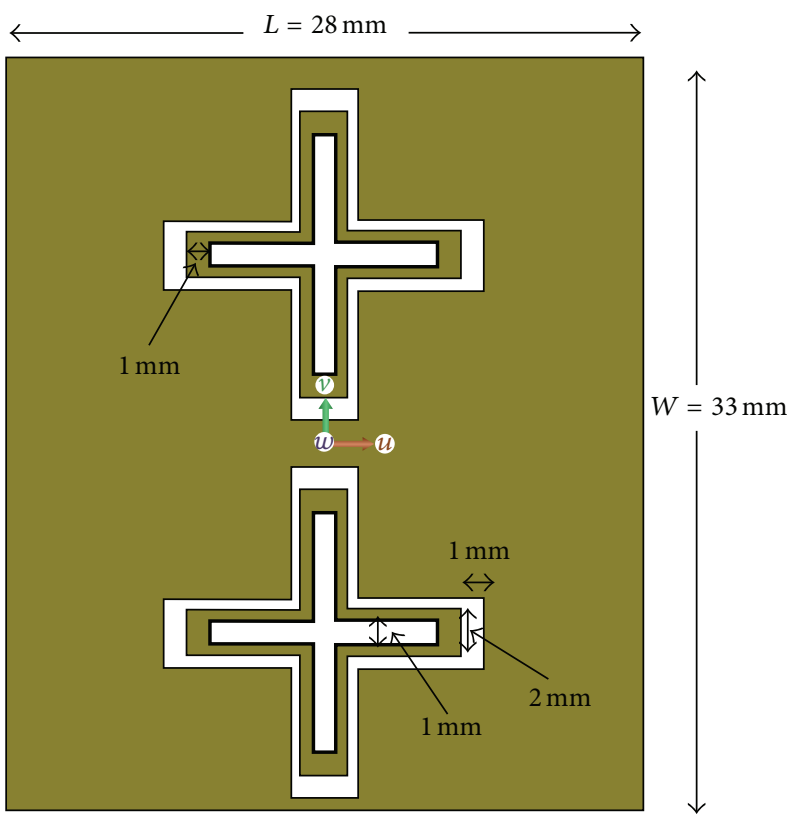

Figure 3: Design geometry of 3rd iterated plus shape patch.

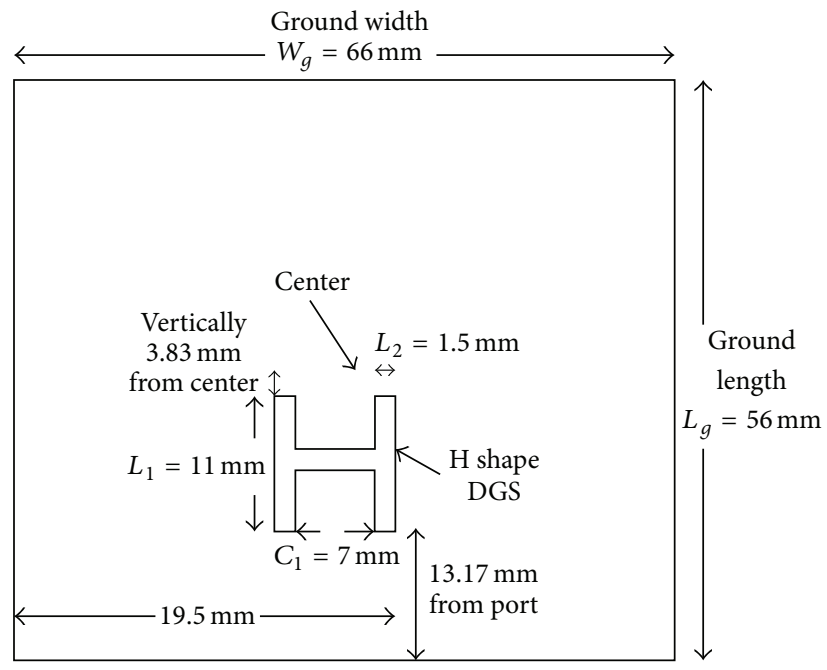

FIGURE 4: Design geometry of DGS on the ground plane of the proposed antenna.

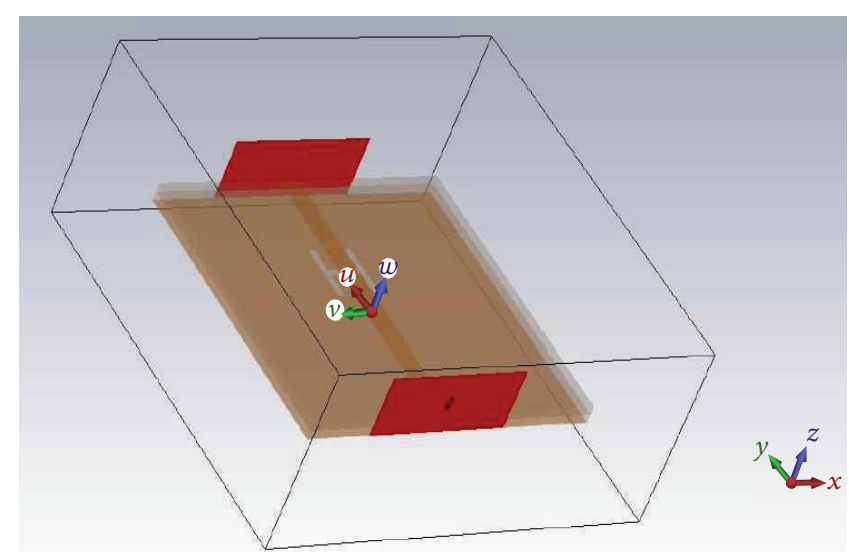

FIGURE 5: Setup of H-DGS under $50 \Omega$ strip line in CST Microwave Studio to extract $S_{21}$ parameters. 


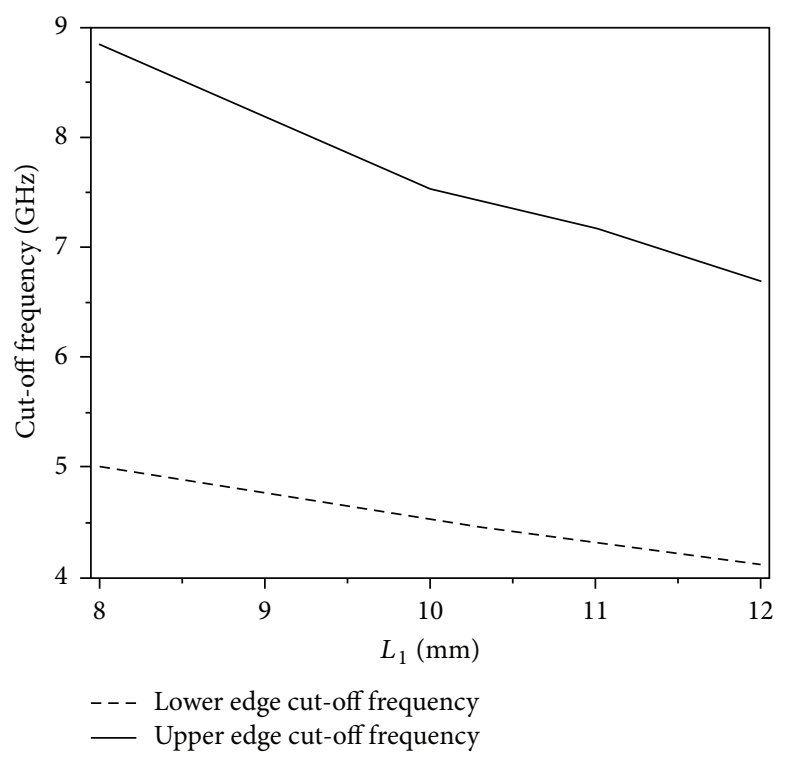

FIGURE 6: Effect of variation of $L_{1}$ on cut-off frequency of DGS as band stop filter.

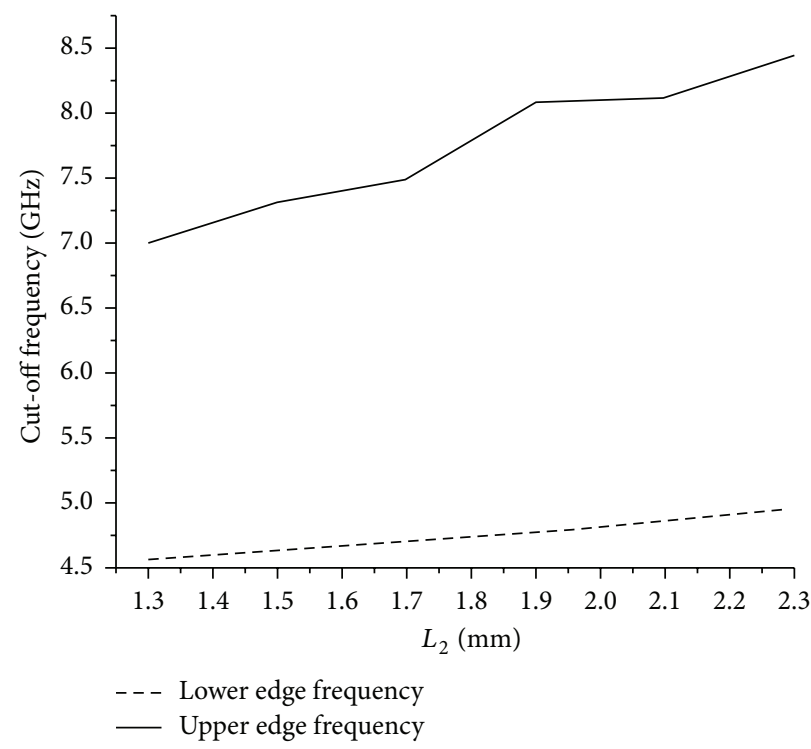

FIGURE 7: Effect of variation of $L_{2}$ on cut-off frequency of DGS as band stop filter.

frequencies is shown in Figures 6,7, and 8. These figures show that as the arm length $\left(L_{1}\right)$ of DGS and the gap $\left(C_{1}\right)$ between two arms increase, frequency of upper edge and lower edge decreases and as thickness of both arms $\left(L_{2}\right)$ increases, frequency of upper edge and lower edge increases. For getting the desired value of stop band frequencies, dimensions of H-DGS $\left(L_{1}, L_{2}\right.$, and $\left.C_{1}\right)$ have been optimized by CST Microwave Studio software and $L_{1}=11 \mathrm{~mm}, L_{2}=1.5 \mathrm{~mm}$, and $C_{1}=5 \mathrm{~mm}$ have been considered for upper edge $4.62 \mathrm{GHz}$ and lower edge $7.19 \mathrm{GHz}$ frequency. For desired band stop characteristics, the values of the $L C$ equivalent model have been extracted by diplexer filter software.

The LC equivalent model of DGS has been shown in Figure 9. The equivalent $L C$ model of DGS has been simulated by Advance Digital System (ADS) software and its $S_{21}$ response has been compared with that of CST Microwave Studio, as shown in Figure 10. Even though there is a difference between the attenuation level at attenuation pole frequency, the $3 \mathrm{~dB}$ bandstop frequency is almost same for ADS and CST Microwave simulation. The reason of mismatch result of attenuation level is that ADS simulate with consideration of infinite ground plane, while in CST Microwave Studio finite ground plane has been considered.

\section{Results and Discussion}

The geometry of the proposed microstrip antenna has been optimized and simulated with CST Microwave Studio. Figure 11 shows the simulated return losses of the 
TABLE 1: Comparison of conversional rectangular patch antenna with various fractal slot iterations of antenna.

\begin{tabular}{|c|c|c|c|c|c|c|c|c|c|c|c|}
\hline Iteration & $\begin{array}{c}\text { Resonating } \\
\text { frequency } \\
(\mathrm{GHz})\end{array}$ & $\begin{array}{l}\text { Number of } \\
\text { higher } \\
\text { harmonics }\end{array}$ & $\begin{array}{l}\text { Return } \\
\text { loss (dB) }\end{array}$ & VSWR & $\begin{array}{l}\text { Gain } \\
(\mathrm{dB})\end{array}$ & $\begin{array}{l}\text { Radiation } \\
\text { efficiency } \\
(\%)\end{array}$ & $\begin{array}{l}\text { Bandwidth of } \\
\text { fundamental } \\
\text { resonance } \\
\text { frequency }(\%)\end{array}$ & $\begin{array}{l}\text { higher } \\
\text { harmonics }\end{array}$ & $\begin{array}{l}\text { Bandwidth } \\
\text { of } 2 \text { nd } \\
\text { harmonics } \\
(\%)\end{array}$ & $\begin{array}{l}\text { Patch } \\
\text { size } \\
\left(\mathrm{mm}^{2}\right)\end{array}$ & $\begin{array}{c}\text { Size } \\
\text { reduction } \\
(\%)\end{array}$ \\
\hline 0 & 2.42 & 1 & -12.53 & 1.61 & 6.3 & 67.6 & 2.46 & 2.90 & - & 1725 & - \\
\hline 1 st & 2.43 & 2 & -13.44 & 1.54 & 3.3 & 55.4 & 3.27 & 2.64 & 5.08 & 983.25 & 43 \\
\hline 2nd & 2.42 & 2 & -22 & 1.17 & 3.8 & 51.2 & 3.30 & 9.19 & 4.34 & 983.25 & 43 \\
\hline $3 \mathrm{rd}$ & 2.42 & 2 & -27 & 1.2 & 4.16 & 51.5 & 3.27 & 2.29 & 4.93 & 983.25 & 43 \\
\hline $\begin{array}{l}\text { 3rd with } \\
\text { H-DGS }\end{array}$ & 2.45 & 0 & -23.26 & 1.14 & 4.46 & 63.8 & 3.68 & - & - & 932 & 46 \\
\hline
\end{tabular}

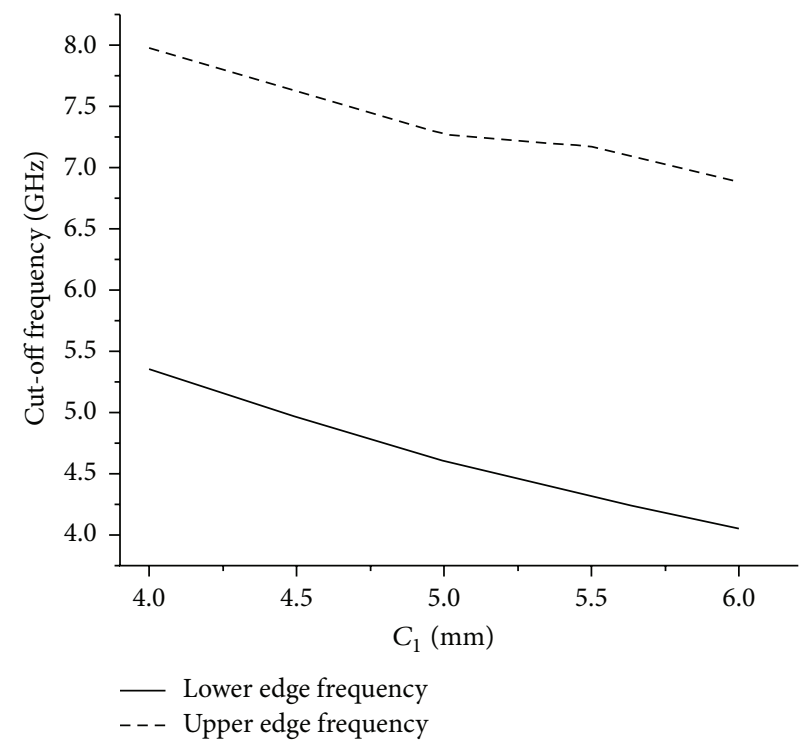

FIGURE 8: Effect of variation of $C_{1}$ on cut-off frequency of DGS as band stop filter.

conventional antenna and all iteration antennas. It can be observed that, besides fundamental mode, the conventional rectangular antenna gives higher harmonics, which are not useful. Here, to reduce the size of the radiating element, slot technique is used. In simulation, by taking different slots, we found that plus shape slot gives the maximum size reduction factor and also does not have any adverse effect on the desired characteristics of the patch antenna. To increase the gain of the antenna, the space of the plus shape slot used with an innovative method and copper layer is etched in the space of the slot. To further increment in the gain, again the same method is repeated ( 2 nd iteration). Table 1 shows that 1 st, $2 \mathrm{nd}$, and $3 \mathrm{rd}$ iterations reduce the size of the conventional antenna by $43 \%$. By etching H-DGS at the ground plane, the size of fractal slot antenna further reduced by $3 \%$ and the bandwidth is enhanced from $2.46 \%$ to $3.68 \%$. Table 1 shows that as iterations increase from 1 st to $3 \mathrm{rd}$, the gain of the antenna at resonance frequency increases. This is according to babinet's principle [2], which states that each slot acts as a radiator and gives contribution in gain of the antenna.

Table 1 shows that, after 1st iteration, if one more iteration is introduced, that is, in 2nd iteration antenna, VSWR improves due to matching and thus radiation loss also improves. The gain of the 2 nd iteration antenna also increases according to babinet's principle, but radiation efficiency decreases due to increment in the bandwidth of 1st harmonics. Similarly, 3rd iteration antenna gives more gain at a fundamental resonance frequency as compared to 2 nd iteration antenna. The 3rd iteration antenna has two higher harmonics, by introducing H-DGS at the ground plane, the size of an antenna further reduced by $3 \%$ as compared to 3 rd iterated antenna without DGS, and due to the reduction of the size of an antenna, the 2 nd harmonics are suppressed by about $14.75 \mathrm{~dB}$. The 1st harmonics generated in 3rd iterated antenna are suppressed by about $6.89 \mathrm{~dB}$ as shown in Figure 12. This suppression occurred due to band stop characteristics of $\mathrm{H}$ DGS. Due to suppression of higher harmonics by H-DGS, the power wastage reduced and thus radiation efficiency increased as compared to 1st, 2nd, and 3rd iteration antennas without DGS, as shown in Table 1.

Figure 13 shows simulated current distribution on plus shaped slot, which shows that most of the current density concentrates on the joints and edges. Figure 14 plots measured and simulated $\mathrm{H}$-plane and E-plane radiation patterns of the 3rd iteration plus the slot antenna witH-DGS at $2.42 \mathrm{GHz}$ resonance frequency. 


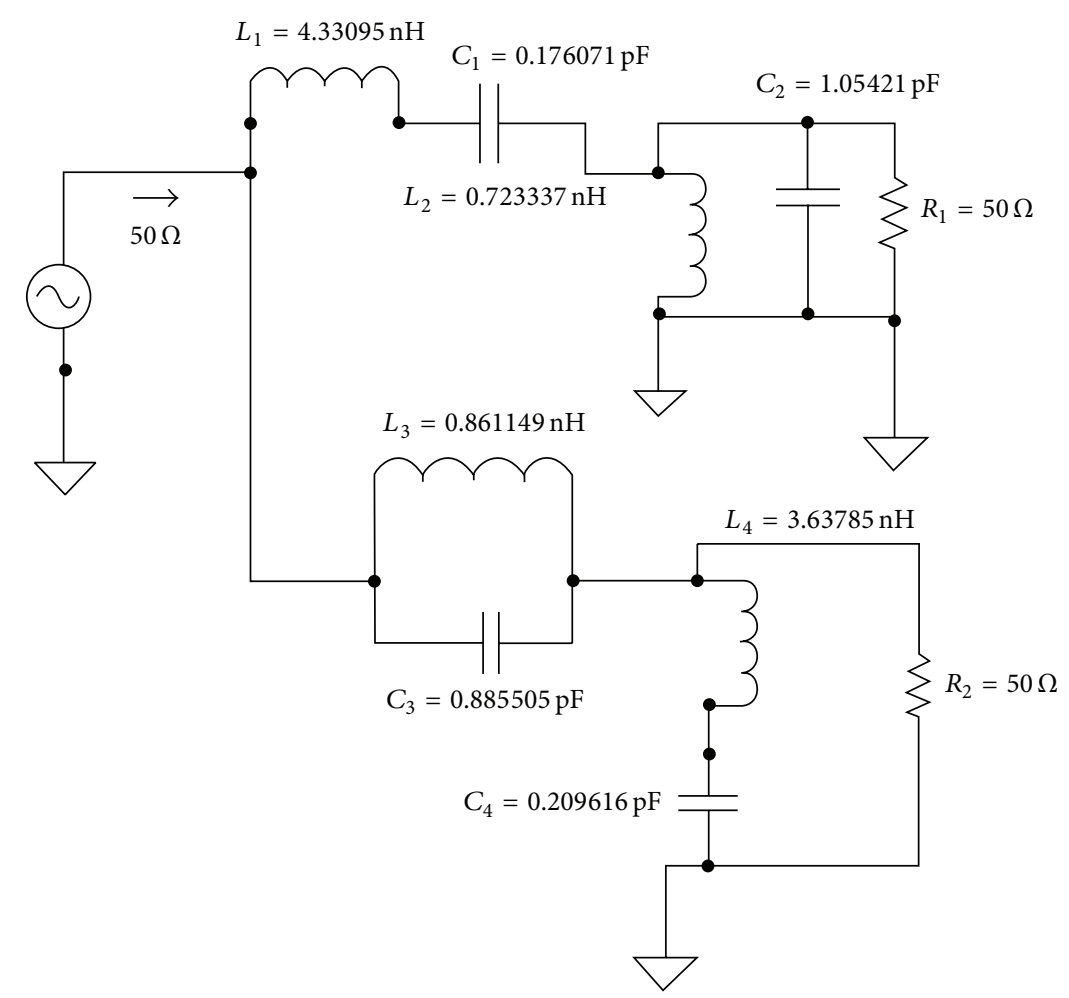

FIGURE 9: Equivalent LC model of $\mathrm{H}$ shape DGS.

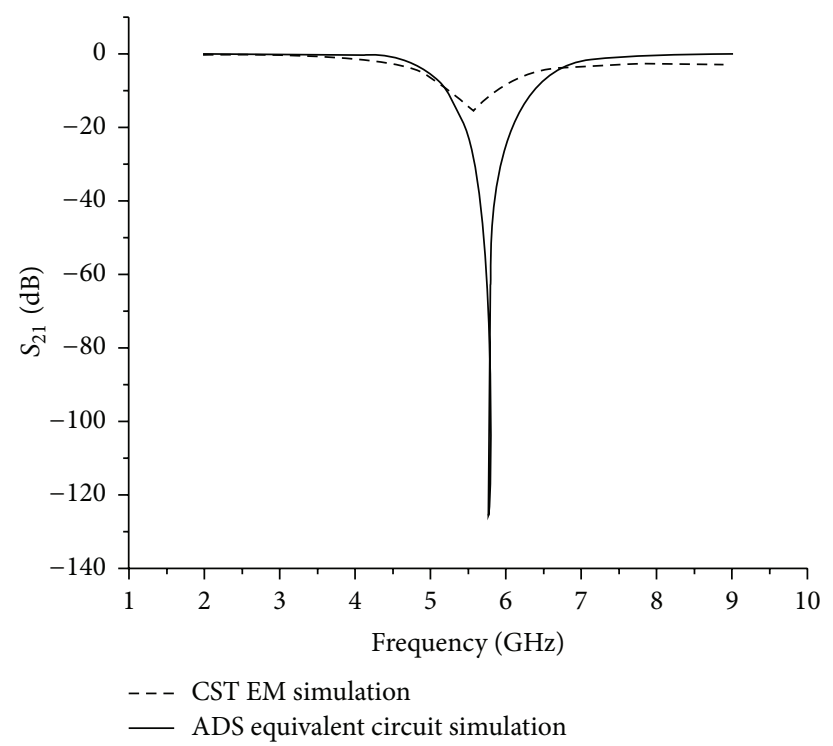

FIGURE 10: $S_{21}$ parameter of $L C$ equivalent model compared with that of H-DGS.

\section{Conclusion}

To obtain an impedance matching, high radiation efficiency, higher harmonic suppression, and the size reduction, a novel type of 3rd iteration plus shape fractal slot antenna has been proposed. By introducing fractal slots, VSWR improves and the size of an antenna reduces, but it also generates higher harmonics. To suppress higher harmonics, H shape DGS and its equivalent circuit have been proposed. The parameter extraction method for the proposed H-DGS has also been explained. Furthermore, by employing the extracted parameters, the band stop characteristics of H-DGS are explained, which suppressed higher harmonics. The radiated power of the proposed antenna in 1st and 2nd harmonic frequency is 


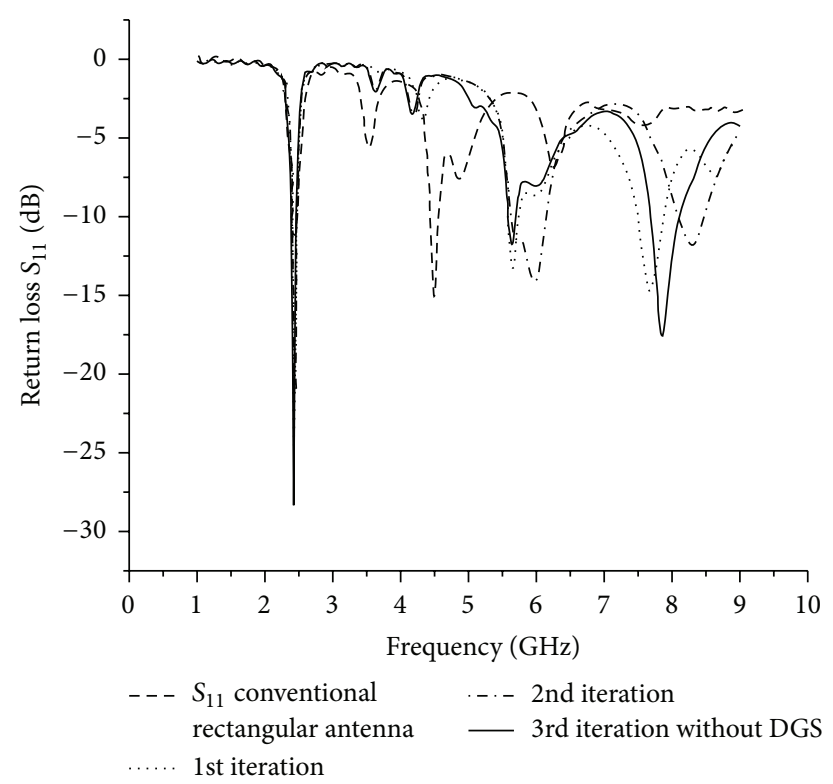

FIGURE 11: Simulated return losses $S_{11}$ of conventional rectangular antenna and 1st to 3rd iterated plus fractal slot antennas.

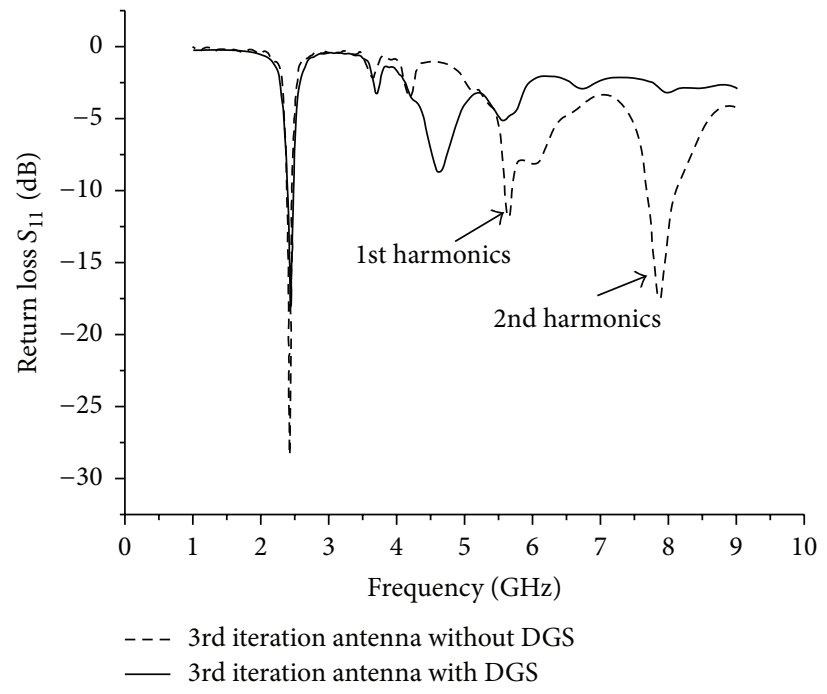

FIGURE 12: Comparison of return loss of 3rd iterated antenna with and without DGS.

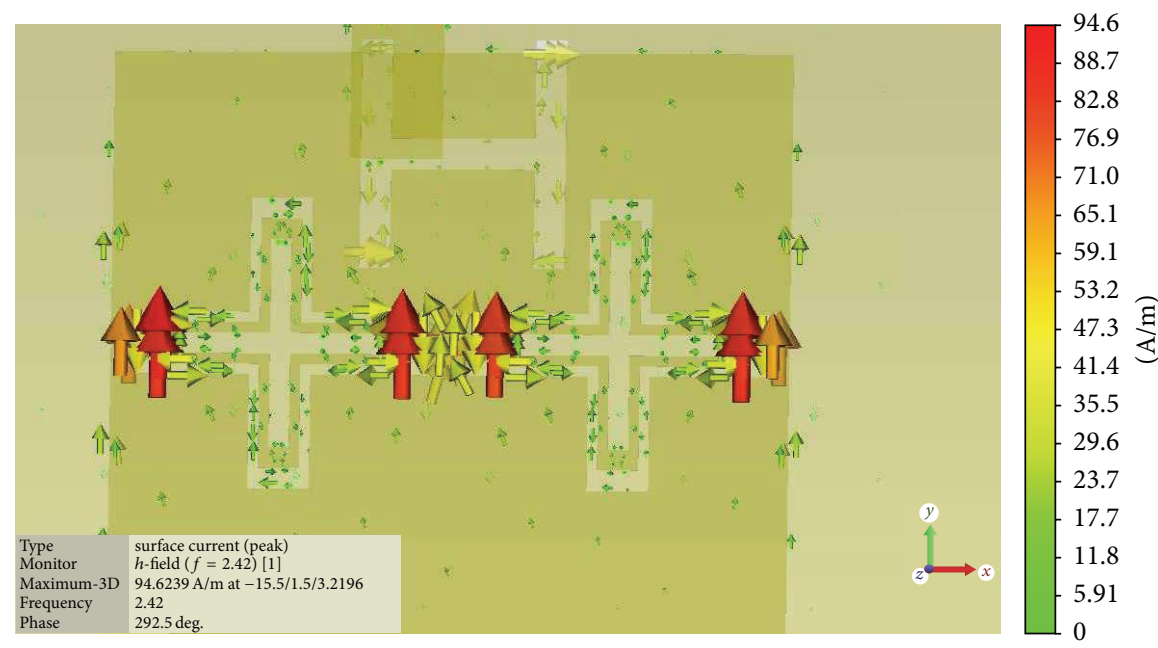

FIGURE 13: Current distribution in 3rd iteration fractal slot antenna witH-DGS. 


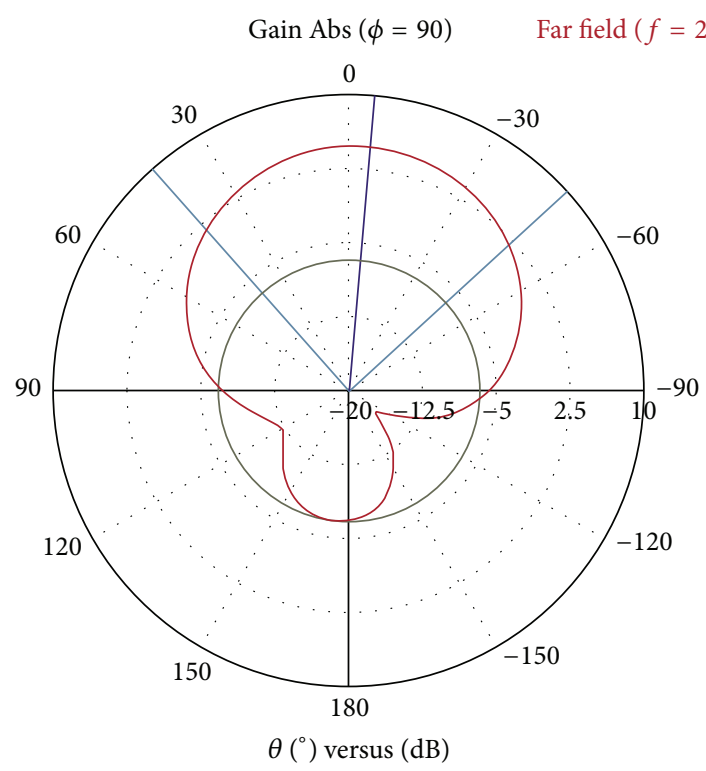

Frequency $=2.42$

Main lobe magnitude $=4.8 \mathrm{~dB}$

Main lobe direction $=-5.0 \mathrm{deg}$.

Angular width $(3 \mathrm{~dB})=88.9 \mathrm{deg}$.

Side lobe level $=-11.5 \mathrm{~dB}$

(a)

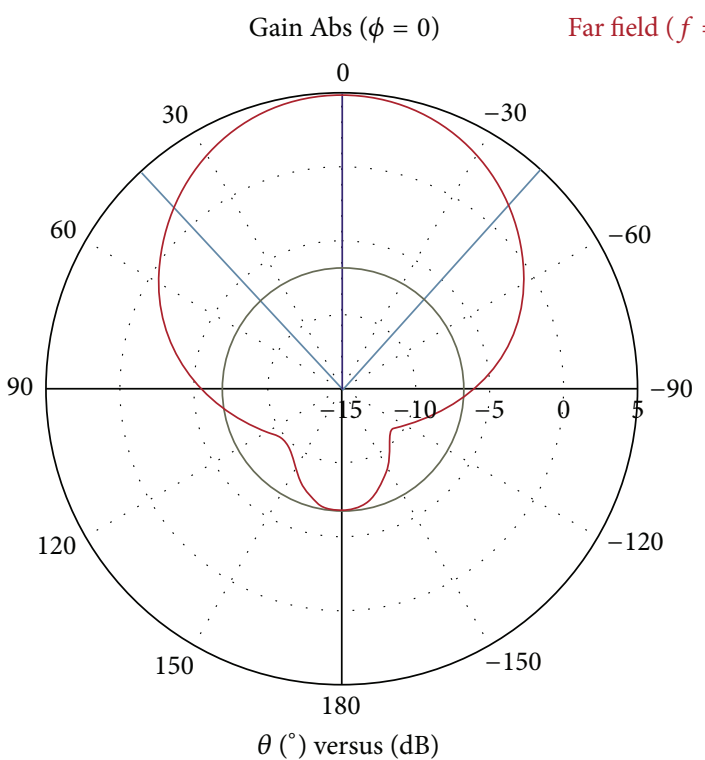

Frequency $=2.42$

Main lobe magnitude $=4.8 \mathrm{~dB}$

Main lobe direction $=0.0 \mathrm{deg}$.

Angular width $(3 \mathrm{~dB})=85.0 \mathrm{deg}$.

Side lobe level $=-11.6 \mathrm{~dB}$

(b)

FIGURE 14: Simulated radiation pattern of 3rd iteration fractal slot antenna witH-DGS: (a) E-plane, (b) H-plane.

very low. The proposed DGS unit and its equivalent circuit could also find applications like microwave filter, coupler, power divider, and so forth.

\section{Conflict of Interests}

The author declares that there is no conflict of interests regarding the publication of this paper.

\section{Acknowledgments}

The author is thankful to G. H. Patel College of Engineering and Technology, Gujarat, for providing access of ADS Simulation software and the management of A. D. Patel Institute of Technology and Charutar Vidyamandal, Gujarat, India, for motivation and support for the research work.

\section{References}

[1] G. Kumar and K. P. Ray, Broadband Microstrip Antennas, Artech House, 2003.

[2] C. A. Balanis, Antenna Theory: Analysis and Design, Wiley Publication, 2nd edition, 2007.

[3] X. Tang, H. Wong, Y. Long, Q. Xue, and K. L. Lau, "Circularly polarized shorted patch antenna on high permittivity substrate with wideband," IEEE Transactions on Antennas and Propagation, vol. 60, no. 3, pp. 1588-1592, 2012.
[4] J. G. Joshi, S. S. Pattnaik, S. Devi, and M. R. Lohokare, "Bandwidth enhancement and size reduction of microstrip patch antenna by magneto inductive waveguide loading," Wireless Engineering and Technology, vol. 2, no. 2, pp. 37-44, 2011.

[5] R. Chair, C.-L. Mak, K.-F. Lee, K.-M. Luk, and A. A. Kishk, "Miniature wide-band half U-slot and half E-shaped patch antennas," IEEE Transactions on Antennas and Propagation, vol. 53, no. 8, pp. 2645-2652, 2005.

[6] A. Kordzadeh and F. H. Kashani, "A new reduced size microstrip patch antenna with fractal shaped defects," Progress in Electromagnetics Research B, vol. 11, pp. 29-37, 2009.

[7] Z. Harouni, L. Osman, and A. Gharsallah, "Efficient $2.45 \mathrm{GHz}$ proximity coupled microstrip patch antenna design including harmonic rejecting device for microwave energy transfer," in Proceedings of the International Renewable Energy Congress (IREC '10), pp. 73-75, Sousse, Tunisia, November 2010.

[8] Y. Horri and M. Tsutsumi, "Harmonic control by photonic bandgap on microstrip patch antenna," IEEE Microwave and Guided Wave Letters, vol. 9, no. 1, pp. 13-15, 1999.

[9] H. Liu, Z. Li, X. Sun, and J. Mao, "Harmonic suppression with photonic bandgap And defected ground structure for a microstrip patch antenna," IEEE Microwave and Wireless Components Letters, vol. 15, no. 2, pp. 55-56, 2005.

[10] X. Lin, L. Wang, and J. Sun, "Harmonic suppression by photonic bandgap on CPW fed loop slot antenna," Microwave and Optical Technology Letters, vol. 41, pp. 154-156, 2004.

[11] Z. Zakaria, W. Y. Sam, M. Z. A. A. Aziz, A. A. M. Isa, and F. M. Johar, "Design of integrated rectangular SIW filter and 
microstrip patch antenna," in Proceedings of the 5th IEEE AsiaPacific Conference on Applied Electromagnetics (APACE '12), pp. 137-141, Melaka, Malaysia, December 2012.

[12] O. A. Nova, J. C. Bohórquez, N. M. Peña, G. E. Bridges, L. Shafai, and C. Shafai, "Filter-antenna module using substrate integrated waveguide cavities," IEEE Antennas and Wireless Propagation Letters, vol. 10, pp. 59-62, 2011.

[13] J.-S. Lim, J.-S. Park, Y.-T. Lee, D. Ahn, and S. Nam, "Application of defected ground structure in reducing the size of amplifiers," IEEE Microwave and Wireless Components Letters, vol. 12, no. 7, pp. 261-263, 2002.

[14] A. K. Arya, M. V. Kartikeyan, and A. Patnaik, "Defected ground structure in the perspective of microstrip antennas: a review," Frequenz, vol. 64, no. 5-6, pp. 79-84, 2010.

[15] M. K. Mandal and S. Sanyal, "A novel defected ground structure for planar circuits," IEEE Microwave and Wireless Components Letters, vol. 16, no. 2, pp. 93-95, 2006.

[16] A. Boutejdar, A. Omar, E. P. Burte, and R. Mikuta, "An improvement of defected ground structure lowpass/bandpass filters using $\mathrm{H}$-slot resonators and coupling matrix method," Journal of Microwaves, Optoelectronics and Electromagnetic Applications, vol. 10, no. 2, pp. 295-307, 2011.

[17] S. K. Parui and S. Das, "Modeling of modified split ring type defected ground structure and its application as bandstop filter," Radioengineering, vol. 18, no. 2, pp. 149-154, 2009.

[18] P. R. Prajapati, A. Patnaik, and M. V. Kartikeyan, "Design and characterization of an efficient multi-layered circularly polarized microstrip antenna," International Journal of Microwave and Wireless Technologies, 2015.

[19] W. T. Li, X. W. Shi, and O. Q. Hei, "Novel planar UWB monopole antenna with triple band-notched characteristics," IEEE Antennas and Wireless Propagation Letters, vol. 8, pp. 1094-1098, 2009.

[20] D. Guha, C. Kumar, and S. Pal, "Improved cross-polarization characteristics of circular microstrip antenna employing arcshaped Defected Ground Structure (DGS)," IEEE Antennas and Wireless Propagation Letters, vol. 8, pp. 1367-1369, 2009.

[21] D. Guha, S. Biswas, M. Biswas, J. Y. Siddiqui, and Y. M. M. Antar, "Concentric ring-shaped defected ground structures for microstrip applications," IEEE Antennas and Wireless Propagation Letters, vol. 6, no. 1, pp. 402-405, 2006.

[22] D. Nashaat, H. A. Elsadek, E. Abdallah, H. Elhenawy, and M. F. Iskander, "Multiband and miniaturized inset feed microstrip patch antenna using multiple spiral-shaped defect ground structure (DGS)," in Proceedings of the Antennas and Propagation Society International Symposium (APSURSI '09), pp. 1-4, IEEE, Charleston, SC, USA, June 2009. 

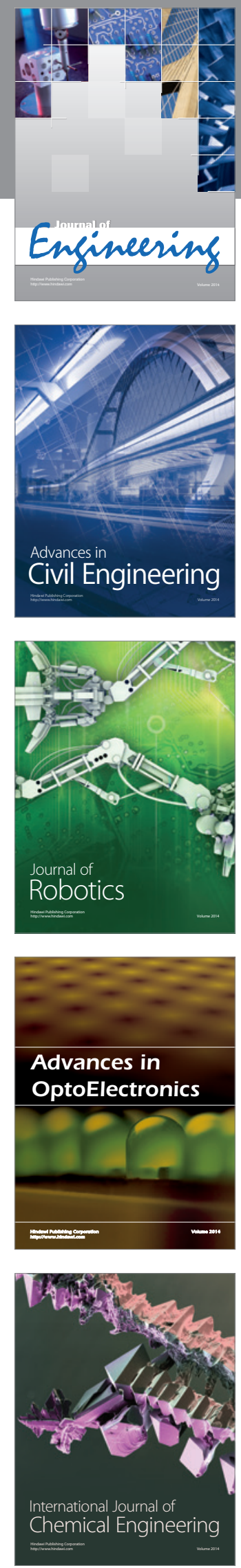

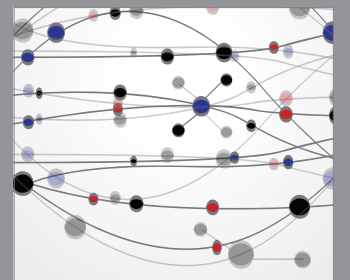

The Scientific World Journal
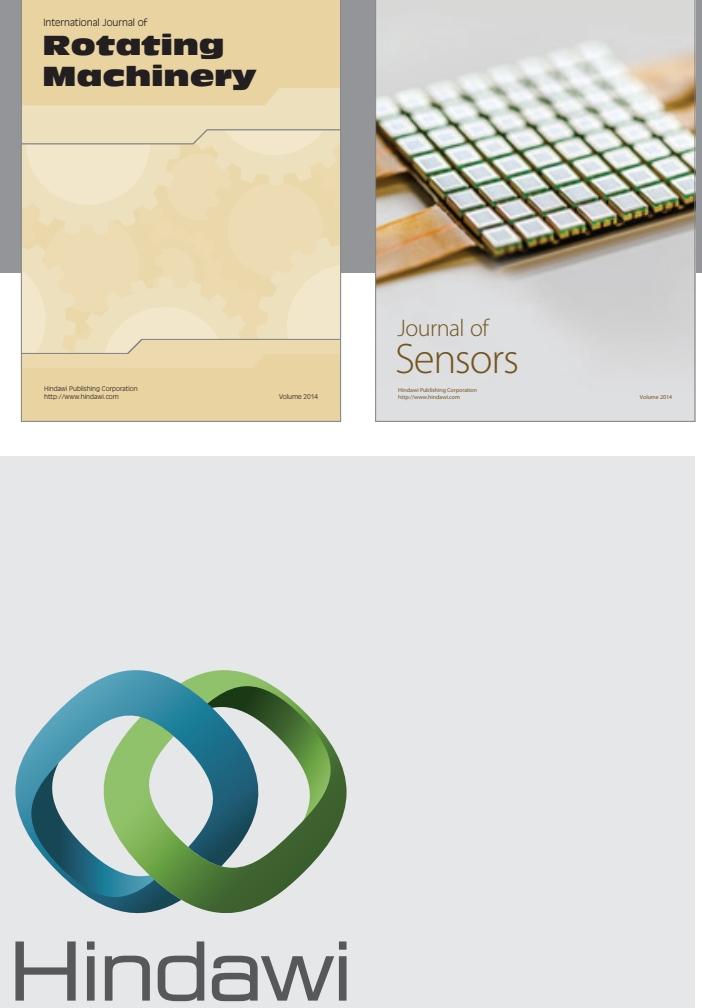

Submit your manuscripts at http://www.hindawi.com
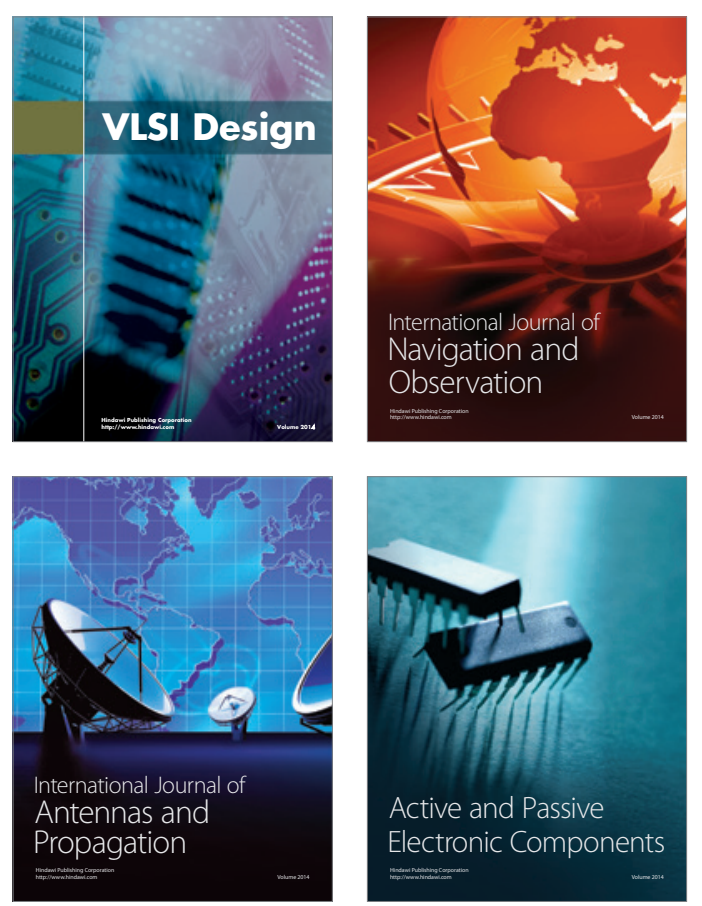
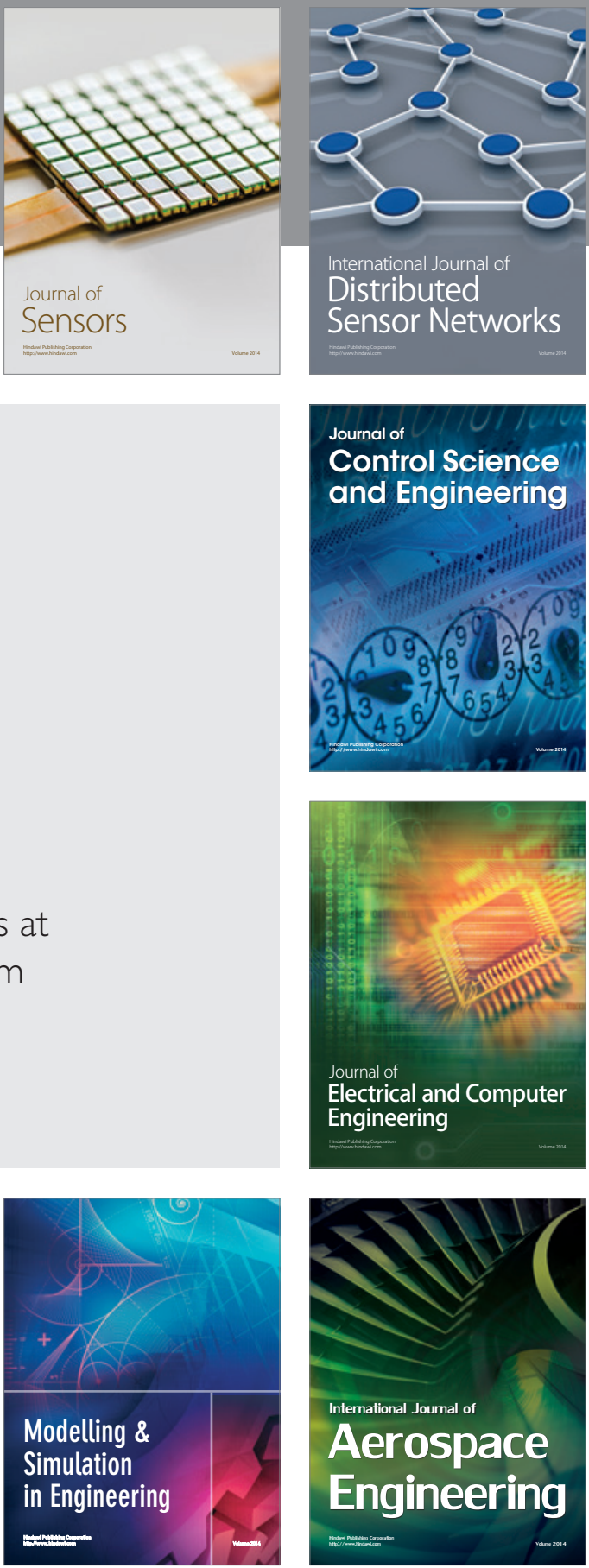

Journal of

Control Science

and Engineering
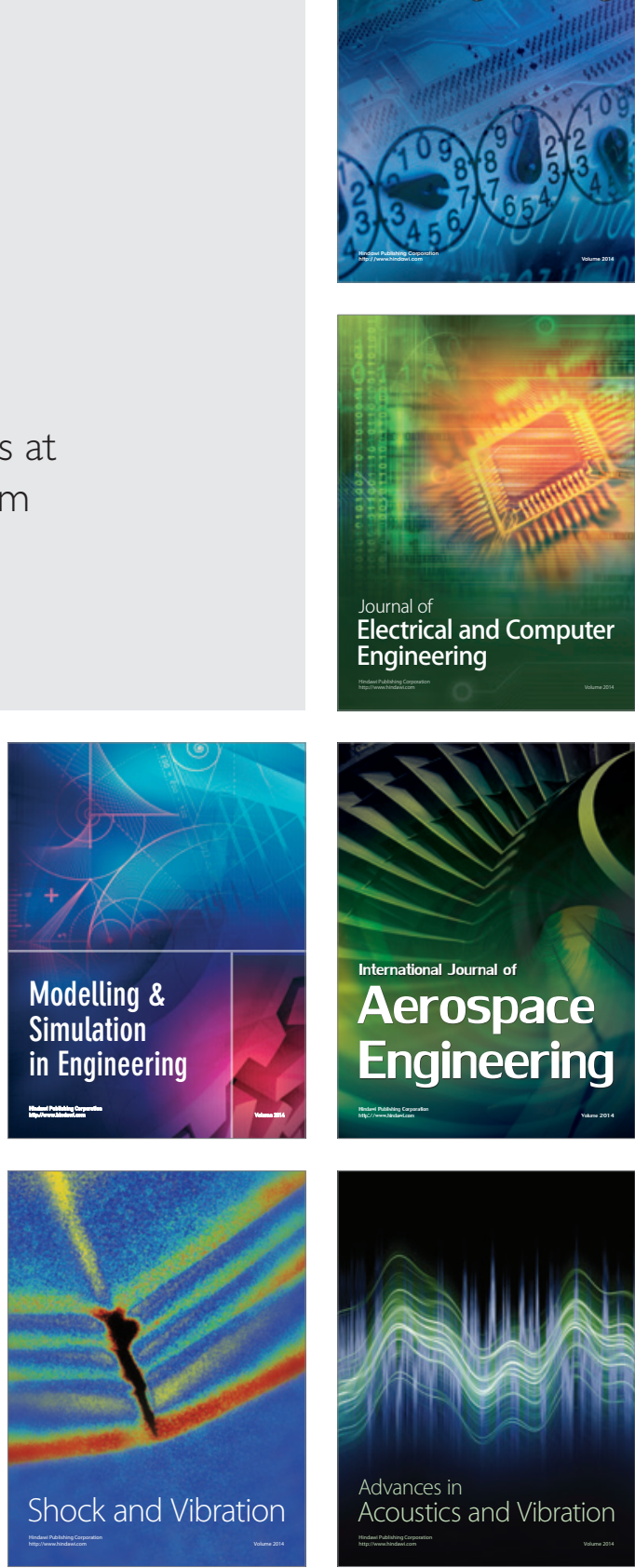